\title{
Capítulo 6 - Ativismo e construção de significado: a política de AIDS do governo federal
}

\author{
Mariana Gomes Cartaxo
}

\section{SciELO Books / SciELO Livros / SciELO Libros}

CARTAXO, M. G. Ativismo e construção de significado: a política de AIDS do governo federal. In: ABERS, R. N., ed. Ativismo institucional: criatividade e luta na burocracia brasileira [online]. Brasília: Editora UnB, 2021, pp. 221251. ISBN: 978-65-5846-159-3. https://doi.org/10.7476/9786558461593.0007.

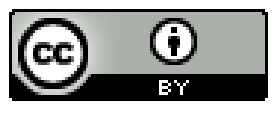

All the contents of this work, except where otherwise noted, is licensed under a $\underline{\text { Creative }}$ Commons Attribution 4.0 International license.

Todo o conteúdo deste trabalho, exceto quando houver ressalva, é publicado sob a licença Creative Commons Atribição 4.0.

Todo el contenido de esta obra, excepto donde se indique lo contrario, está bajo licencia de la licencia Creative Commons Reconocimento 4.0. 


\section{Capítulo 6}

\section{Ativismo e construção de significado: a política de AIDS do governo federal ${ }^{1}$}

Mariana Gomes Cartaxo

\section{Introdução}

Os estudos sobre o Estado estão geralmente voltados para a compreensão dos fenômenos institucionais em seu nível sistêmico, ao direcionar o olhar para a estrutura e para os seus arranjos macro. A dimensão subjetiva dos atores que ocupam as instituições do governo ainda é um território analítico em processo de exploração. A literatura sobre interacionismo simbólico propõe uma expansão da análise da ação social para abarcar a construção de significados e a interação como processos constituintes das instituições humanas (HALLET; VENTRESCA, 2006). Isso implica em observar regras, normas

1 Este capítulo é uma versão retrabalhada de algumas das discussões levantadas em minha dissertação. Para discussões mais aprofundadas de outros temas, ver Cartaxo (2018). 
e processos que guiam as instituições com as pessoas que as aplicam e que também constroem significados sobre o lugar que ocupam.

No Brasil, a consolidação de um Estado heterogêneo (ABERS; SERAFIM; TATAGIBA, 2014) trouxe à tona uma dinâmica peculiar de construção institucional. No âmbito federal, a integração de burocratas no Estado acabou por incorporar uma série de atores provenientes de movimentos sociais nos quadros do funcionalismo público. Para além disso, o processo de concepção das políticas públicas na virada do século foi motivado pela mobilização de diversos grupos sociais, que depois de um longo período ditatorial passaram a ter espaço para suas demandas (MISCHE, 1997; MENICUCCI, 2007). Dessa forma, o contexto histórico local é extremamente significativo para se compreender as instituições e políticas públicas no país.

A política federal de AIDS é um dos exemplos de políticas que surgiram na onda de democratização do Brasil e que tiveram, em sua construção, a presença de diversos atores de movimentos sociais. Desde o início, o desconhecimento sobre a doença e a presença de figuras como o ativista Betinho deram uma carga emocional e simbólica muito forte para a urgência da resposta nacional ao vírus. O processo de incorporação desse problema de saúde pública ao Sistema Único de Saúde (SUS), contando com ajuda internacional e com a participação de ativistas na gestão (RICH, 2013), criou uma política altamente especializada e com uma estrutura forte e independente. Nos dias de hoje, o avanço técnico e científico ajudou a "normalizar" o problema na sociedade, mas não foi suficiente para lidar com esse grande desafio que afeta, segundo levantamento de 2017, 882 mil brasileiros (SVS/DIAHV/BOLETIM EPIDEMIOLÓGICO, 2017). Lidar com os resquícios de um passado nebuloso e enfrentar o futuro é o que movimenta a construção da resposta de vários dos atores alocados em instituições estatais. Nesse processo, muitos significados são criados sobre o papel da instituição em atender demandas contemporâneas.

A resposta do Estado brasileiro à AIDS é construída em sua maioria por gestores técnicos e pela diretoria do atual Departamento de Infecções Sexualmente Transmissíveis, AIDS e Hepatites Virais (Diahv). São esses burocratas os responsáveis por criar as diretrizes da política pública no âmbito federal e trabalhar na coordenação dos recursos para os estados e municípios. Por estarem em contato direto com movimentos sociais, os 
gestores muitas vezes são os responsáveis por traduzir os interesses da sociedade civil em aplicações concretas. Ao atuar nessa ponte, esses indivíduos precisam encontrar formas de aplicar a agenda dentro da estrutura administrativa do Ministério da Saúde.

Levando isso em conta, este capítulo pretende lançar luz sobre certas lacunas no funcionamento do Estado por meio do burocrata na política de AIDS e de suas interpretações sobre o papel da instituição. Partimos do pressuposto de que instituições são habitadas (HALLETT; VENTRESCA, 2006) e que, para compreendê-las, é preciso adentrar o mundo dos atores e captar suas impressões sobre os fenômenos institucionais. Dessa forma, voltamos nosso olhar para os gestores da política de AIDS e procuramos compreender como a origem ativista do órgão expressa e molda as narrativas empregadas por essas pessoas.

Com base em 21 entrevistas e na análise de documentos históricos, observamos os conceitos mobilizados pelos atores ao longo dos anos da política pública. A história ajudou a fundar uma narrativa interna de autonomia e independência organizacional em relação a outros quadros do Ministério da Saúde. Ao examinar as percepções subjetivas em momentos de transformação política, percebemos que, para esses atores, a mobilização dentro do Estado é construída principalmente por meio da socialização dos funcionários e por influência do histórico do departamento.

Partimos de uma mudança organizacional importante - a transformação do programa em departamento em 2009 - para entender as interpretações sobre dois momentos institucionais distintos. Procuramos analisar como as mudanças afetaram a ordem estabelecida, fundada especialmente pela legitimidade informal e por redes consolidadas de autonomia administrativa.

Considera-se que, ao estudar o ativismo como um conceito importante para se compreender os burocratas, a dimensão simbólica é fundamental para observar como as redes sociais e a interação entre os atores possibilitaram a construção de uma narrativa ativista. Para ampliar as possibilidades de compreensão dessa dimensão simbólica da ação, o ativismo também compõe as diferentes narrativas institucionais existentes. Somando-se às diversas pesquisas que trabalham sobre o tema de ativismo institucional no Brasil (VIANA, 2017; SANTIAGO, 2017; BRANDÃO; VIANA, 2016; BRANDÃO; VILAÇA, 2017; OLIVEIRA, 2016; VILAÇA, 2017), este 
capítulo pretende mobilizar a literatura sobre ação e construção de significado para avançar a análise sobre o ativismo dentro do Estado. Dessa forma, espera-se ultimamente ampliar os estudos sobre os atores que participam da gestão governamental, abrindo a "caixa preta do Estado" (ABERS; SERAFIM; TATAGIBA, 2014).

A presente pesquisa está dividida em três seções. Na primeira, apresentamos uma reflexão sobre o estudo da ação e a análise das instituições. Na seção seguinte, descrevemos a política de AIDS, reconstruindo historicamente a sua importância política e dando contexto a sua relativa autonomia institucional. Esclarecemos, ainda, a mudança institucional de programa para departamento e buscamos contextualizá-la dentro de um processo político mais abrangente. Na terceira seção, analisamos as interpretações dos burocratas sobre essa transformação, e como ela mobilizou diferentes interpretações dos gestores sobre o papel do Diahv e a atuação da política de AIDS dentro do Ministério da Saúde. Por fim, oferecemos, junto às considerações finais, algumas possíveis implicações de pesquisa.

\section{Instituições habitadas e a ação}

A agência é um conceito fundamental para se compreender o papel do indivíduo em processos institucionais. Ao utilizar esse conceito, partimos do pressuposto de que as pessoas têm a capacidade de agir sobre o meio de acordo com influências internas e externas. Compreender a construção e a mobilização dessas concepções pessoais é um passo importante para a análise de fenômenos sociais. A agência surge a partir dos conhecimentos do ator sobre as estruturas e de sua habilidade de aplicá-los a outros contextos. Essa possibilidade de mobilizar recursos dentro de um esquema de regras é implícita à ação social (SEWELL, 1992).

As estruturas moldam as configurações da agência por meio de marcadores sociais - tais como renda, gênero, classe, etnia, entre outros - que possam restringir ou possibilitar a ação. Cada característica da estrutura proporciona aos atores um conhecimento diferente acerca dos esquemas e estabelece acessos distintos aos recursos, isto é, "as estruturas e as agências humanas que as dotam são carregadas de diferenças de poder” (SEWELL, 
1992, p. 21, tradução nossa). ${ }^{2}$ A partir da proposta de Sewell, podemos entender como as formas de agir no mundo variam de acordo com as condições dos indivíduos, e como estas modulam suas capacidades e práticas.

Não obstante, o indivíduo, além de estar imerso em arranjos estruturais, também está fadado a viver em sociedade. A construção de relações sociais é um aspecto importante para se compreender a agência humana, e as redes são instrumentos poderoso para a ação. Nesse sentido, Emirbayer e Goodwin (1994) propõem incluir no debate a abordagem relacional, por meio de redes sociais. Essa perspectiva analítica permite a investigação de dimensões que constrangem e habilitam as relações entre os atores sociais dentro de um sistema. Os autores defendem um maior protagonismo das estruturas e dos papéis sociais dos atores.

Para esses teóricos, é preciso reconhecer que a estrutura possui um caráter relacional e que está embasada em arranjos concretos. A autonomia individual não é concebida sozinha, ela se faz possível por meio de várias estruturas e pela formação da identidade. Essa compreensão é importante para enxergar o papel da identidade ${ }^{3}$ e das relações em rede na prática individual dos atores (EMIRBAYER; GOODWIN, 1994).

Em meio ao intenso debate sobre o papel da agência, passou-se a questionar a visão monolítica e distanciada das instituições, onde os estudos institucionalistas focavam intensamente em regras e normas, sem olhar para os processos subjetivos por trás da construção institucional. Questionando essa perspectiva, DiMaggio (1988) defende que a institucionalização deve ser observada como um processo formado por meio da soma de esforços de atores que apoiam, entram em confronto e lutam por uma definição. Dessa forma, as instituições precisam ser reproduzidas constantemente pelos atores, e essa reprodução geralmente é problemática. A ideia de trabalho institucional, posteriormente desenvolvida mais a

2 "Structures, and the human agencies they endow, are laden with differences in power." (SEWELL, 1992, p. 21).

3 A identidade e os seus significados, nessa perspectiva, são uma forma importante de se compreender como uma organização opera a partir das pessoas que a ocupam. As instituições, segundo Hallett e Ventresca (2006, p. 215), “são habitadas por pessoas e suas ações” [“they are 'inhabited' by people and their doings.”] (tradução nossa). 
fundo por Lawrence, Suddaby e Leca (2009), é a de que o trabalho prático dos atores é o que permite que as instituições existam e continuem sendo mobilizadas e transformadas.

A sociabilidade tem implicações claras para as instituições ao influenciar como a burocracia funciona na prática (HALLETT; VENTRESCA, 2006). Hallett e Ventresca extraem dos estudos de Blumer a premissa de que as pessoas agem com base em significados derivados da interação social. Para eles, a ordem social é o resultado de interações dinâmicas ou negociações entre atores. A vida organizacional, deste modo, é produto de um trabalho interativo e constante de construção coletiva de significados sobre a instituição. Compreender os significados é especialmente importante para analisar políticas como a de AIDS, em que um emaranhado de atores de origem governamental e de movimentos sociais consolidaram uma estrutura organizacional bastante peculiar com relação a outras doenças. As redes construídas ao longo do processo de consolidação da política pública formaram sua própria atuação institucional.

A ordem social, para Hallett e Ventresca, é baseada em interações simbólicas entre os atores, e essa dinâmica lhes garante legitimidade informal. Essa legitimidade informal construída pelas redes tem uma forte relação com a atuação dos indivíduos e a autonomia percebida por eles. O conceito de autonomia é constantemente utilizado para descrever aspectos diferentes de uma instituição. Geralmente, buscamos compreender os elementos que possibilitam e facilitam a ação do burocrata e do lugar que ocupa frente às regras impostas. Pensando na construção de significados, nesta pesquisa estamos preocupados em descrever a ideia de autonomia como um debate em aberto entre os gestores e em detalhar como estes mobilizam diferentes conceitos para justificar o efeito das mudanças institucionais em seu trabalho.

Dessa forma, entendemos a questão da autonomia do Diahv como uma “controvérsia”, ${ }^{4}$ porque o tema mobiliza diferentes interpretações acerca do papel da política e de seus posicionamentos. A partir das entrevistas, percebemos

4 Utilizamos o conceito de Viana (2016, p. 16), que entende controvérsia como “diferentes entendimentos e posições por parte dos atores acerca de um problema público, em geral, ancorados em ordens de grandeza ou em racionalidades mais amplas”. 
que as mudanças pelas quais a instituição passou acabaram afetando as percepções sobre autonomia organizacional dos gestores em diferentes níveis.

Pensando nessa construção, a ideia de ativismo se torna especialmente relevante para se compreender quadros de certas políticas públicas. No Brasil, a formação de um Estado heterogêneo (ABERS; SERAFIM; TATAGIBA, 2014) deu espaço para que os movimentos sociais pudessem ocupar cargos na burocracia. Rich (2013) observa que, na política de AIDS brasileira, a formação de burocracias ativistas era bastante marcante. Durante esse processo, as alianças entre burocratas e sociedade civil ajudaram a consolidar o campo no Brasil e a estabelecer as primeiras respostas quando a doença ainda era uma incógnita - do ponto de vista clínico, mas também político e social. Além disso, as alianças com a sociedade civil eram estratégicas por permitir a atuação em lugares onde o Estado não tinha capilaridade suficiente para atuar.

Dentro do Ministério da Saúde, Rich (2013) destaca, ${ }^{5}$ ainda, que diversos ativistas do movimento de AIDS ingressaram na política no nível federal por serem os primeiros especialistas sobre um tema desconhecido. Ao estudar ativismo institucional, defendemos que é preciso voltar o olhar para os atores que, dentro de um ambiente burocrático, exercem sua agência com a intenção de trabalhar sobre uma agenda política. No recorte aqui proposto, voltamo-nos especialmente para as perspectivas do gestor e ao modo como ele cria os significados em diálogo com a história da instituição.

Os atores dentro das instituições são, afinal, os atores responsáveis por implementar e contestar agendas. A partir do diálogo entre diferentes visões, a literatura aqui citada permite observar como essas disputas ${ }^{6}$ se dão em um nível micro (dos atores individuais) e macro (de interesses e decisões mais amplas).

5 A autora nota, além do mais, como esse fenômeno dos ativistas burocratas é comum especialmente na América Latina, percebendo que esses atores tomam posições de liderança dentro da instituição e continuam mobilizando a agenda no Estado.

${ }^{6}$ Isto é, como o contexto acaba por afetar diretamente os atores e suas perspectivas sobre a própria agência. A maneira como o gestor enxerga o seu papel e a instituição em que trabalha é fundamental para compreender a forma como a política pública é organizada e legitimada. 
Transitando entre aspectos externos (estrutura e contexto histórico) e subjetivos (a agência dos gestores), o processo de institucionalização passa por uma mobilização constante dos atores que ocupam o órgão público. A reprodução dos quadros institucionais, feita por meio do trabalho prático dos atores, acontece com base em significados derivados da própria ação social (DIMAGGIO, 1988).

Assim como no trabalho de Gouldner (1954), revisitado por Hallett e Ventresca (2006), pretendemos observar dois momentos institucionais específicos e avaliar as diferentes reações dos envolvidos para extrair as interpretações sobre o papel da instituição. Com base na pesquisa realizada e na esteira de outros autores e autoras, entendemos que a construção da política de AIDS teve uma base ativista que foi determinante na consolidação da política e, dessa forma, a construção de significado para os gestores acabou influenciada por essa perspectiva. Como se verá adiante, por conta do ativismo e da liberdade de trabalho entre as redes hierárquicas consolidadas na instituição, a ideia de autonomia institucional entra em xeque após a mudança.

\section{A política de AIDS do governo federal}

Como ponto de partida, é necessário contextualizar, historicamente, a política de AIDS e como sua origem se entrelaça com a história dos movimentos de luta contra a AIDS no Brasil. Durante o processo de construção da política, há uma relação próxima entre o Estado e os movimentos sociais, além de forte influência de entidades e atores internacionais na consolidação do modelo de resposta nacional.

Em 1981, uma doença pneumática afetando uma série de homens homossexuais foi identificada pelo centro de controle de doenças norte-americano, o Center for Disease Control and Prevention (CDC) (UNAIDS, 2008). Naquele momento, ninguém imaginava que o advento dessa infecção viria a afetar o mundo tão profundamente. Conforme o vírus se disseminou e se tornou um problema mundial de saúde pública, cada país precisou adaptar seus recursos às diversidades e complexidades internas para lidar com a emergência da epidemia de HIV. No início, o desconhecimento das causas e origens do vírus 
criou receio nos governos, que temiam vincular-se ao tema. Por se tratar de uma infecção que afetava especialmente pessoas de grupos à margem da sociedade, as autoridades demoraram a reconhecer a epidemia como problema e responder à crise (UNAIDS, 2008).

A AIDS, ao combinar "comportamento sexual e doença” (GALVÃO, 2000), trouxe à tona uma série de questionamentos e embates entre diferentes concepções de saúde pública. Nesse contexto, a luta por dignidade de pessoas vivendo com HIV foi decisiva para legitimar uma resposta pública a ela.

Durante esse momento histórico, o Brasil passava pelo processo de redemocratização e começou a revisar seu sistema de saúde, que posteriormente foi transformado no atual Sistema Único de Saúde, o SUS. Após um período de repressão ditatorial, os movimentos sociais voltaram à tona clamando por mudanças na esfera política, em especial os grupos de gays, mulheres e pessoas negras (MACRAE, 1990), que dividiam espaço com grupos sindicais "tradicionais". A agenda da luta contra a AIDS, que de início se apresentou como pauta de grupos LGBTs, acabou incorporando diversos movimentos de pessoas à margem da sociedade.

Havia grande heterogeneidade nos movimentos que integravam essa agenda. A fala de um dos entrevistados ilustra essa questão ao notar que os atores que participaram da luta pela política de AIDS eram muito diferentes dos movimentos que protagonizaram a transição para a democracia.

Esse movimento inicial é um movimento que se inicia também no refluxo dos chamados movimentos sociais tradicionais - movimentos sindicais, movimentos corporativos - então esse movimento ele nasce [...] da construção da solidariedade, da ideia de responder a determinadas necessidades que estavam colocadas pelas populações que estavam sendo mais atingidas - movimentos de homossexuais, movimentos de usuários de drogas, movimentos de prostitutas - então esse [...] conjunto de atores era muito diferente dos atores que estavam na esteira [...] do processo de democratização, mas ao mesmo tempo fortalecia [...] o processo [...] porque colocava novas agendas. (Entrevista 1, 6 jan. 2011, Brasília). 
No Brasil, as primeiras matérias editadas sobre a doença nos jornais datam de 1981. Galvão (2000) destaca que a doença chegou antes na mídia do que nos registros oficiais, e isso é um fato importante para se compreender os primeiros anos da resposta. Antes mesmo de se consolidar uma política pública ou de haver informações claras sobre o vírus, a mídia desempenhou o papel de disseminadora de informações sobre o "câncer" ou "praga” gay que mais tarde se mostraram completamente infundadas. Para a autora, a mídia foi a principal responsável por moldar as primeiras respostas ao que ela chama de "mal de folhetim”. Em 1983, os primeiros grupos gays começam a se organizar ao redor da epidemia, pautados especialmente pelos noticiários. Destacam-se os grupos Somos e Outra Coisa. ${ }^{7}$

Esses grupos de militantes gays foram precursores ao cobrar do governo uma resposta adequada ao problema no estado de São Paulo (TEIXEIRA, 1997). Essa cobrança resultou em um grupo de trabalho que posteriormente deu origem ao primeiro programa de controle da AIDS no país (GALVÃO, 2000, p. 57). Em seguida, programas foram criados em mais dez estados brasileiros. Somente em 1985, o governo federal deu sua primeira resposta. Naquele ano, foi assinada a Portaria Federal do Ministério da Saúde $\mathrm{n}^{\circ} 236$ que determinava as diretrizes do "programa de controle da SIDA ou AIDS”. Em 1986, durante o governo Sarney, foi instituído o Programa Nacional de DST e AIDS no Ministério da Saúde, que só foi oficialmente consolidado em 1988. Desde o início, a política de AIDS ficou vinculada a outras DSTs/ISTs. ${ }^{8}$

A Constituição de 1988, além de estabelecer a participação social na saúde pública, também determinou a descentralização da gestão e das políticas de saúde no Brasil, atribuindo responsabilidades compartilhadas entre

7 As primeiras organizações lideradas por pessoas vivendo com HIV surgiram em 1985, o Grupo de Apoio à Vida (Gapa) o Grupo pela Valorização, Integração e Dignidade do Doente de AIDS (Grupo Pela Vida) e a Associação Brasileira Interdisciplinar de AIDS (Abia). Esta última era liderada por Herbert José de Sousa, o Betinho.

8 A sigla atualmente utilizada é Infecções Sexualmente Transmissíveis (ISTs), para destacar "[...] a possibilidade de uma pessoa ter e transmitir uma infecção, mesmo sem sinais e sintomas.” (DIAHV. Disponível em: http://www.aids.gov.br/pt-br/publico-geral/o-quesao-ist. Acesso em: 31 ago. 2018). 
os diferentes níveis de governo. A descentralização impacta diretamente a gestão da política de AIDS, haja vista que o programa nacional não pode intervir diretamente no nível local, deixando aos estados e municípios essa função. Isso torna a política de AIDS responsável por coordenar as diretrizes nacionais e formular e fomentar as políticas públicas sem, contudo, aplicá-las diretamente. Desde o início, a política nacional passou por diferentes designações e é um trabalho complexo identificar cada período e sua respectiva denominação. ${ }^{9}$ Contudo, a instituição contou com relativa estabilidade organizacional e de coordenação. Destaca-se o papel de Lair Guerra como primeira chefe de gestão, sendo pioneira na implementação da política (GALVÃO, 2000, p. 122-123).

O Banco Mundial destinou uma série de empréstimos a países de baixa e média renda a partir do final dos anos 1980 até o início dos anos 2000 para o combate à epidemia de AIDS. A temática era uma das agendas do banco, que tinha o enfoque especialmente em promover ações de prevenção nos países. Como em todo empréstimo promovido por essa organização internacional, os países deveriam entrar com uma contrapartida nacional somada ao montante do banco, e pagar o financiamento ao longo de até 15 anos. Esse foi um ponto de extrema importância para a resposta brasileira à AIDS, pois garantiu autonomia financeira para o funcionamento da política pública.

Lair Guerra foi a responsável por firmar o primeiro empréstimo do Banco Mundial no Brasil - o "Projeto de Controle de AIDS e DST" ou AIDS I, oficialmente sancionado em 1994 - que deu ao órgão recursos financeiros para ações de combate à epidemia. O projeto permitiu que a política tomasse o formato que tem hoje, com o incentivo e aproximação às organizações da sociedade civil e a criação de um "Setor de Articulação com ONG” (GALVÃO, 2000, p. 128). O primeiro projeto tinha o orçamento de 250 milhões de dólares - valores da época - com 160 milhões do Banco Mundial e 90 milhões de contrapartida do Tesouro Nacional.

Em 1996, durante o governo Fernando Henrique Cardoso, é aprovada a lei ${ }^{\circ}$ 9.313, de 13 de novembro de 1996, que autoriza a distribuição gratuita e universal de medicamentos antirretrovirais aos portadores do vírus HIV.

9 Consultar Galvão (2000, p. 18-19) para uma lista de nomes entre 1987 e 1996. 
Desde 1995, o Brasil fabricava o AZT (azidotimidina) ${ }^{10}$ nacionalmente, e outros medicamentos foram incorporados à produção nacional em seguida. Essa iniciativa acabou desagradando farmacêuticas internacionais, e o Brasil foi denunciado na Organização Mundial do Comércio (OMC) pelos Estados Unidos por violar as regras internacionais de patentes em 2001. Após o governo brasileiro ameaçar fazer o licenciamento compulsório da medicação, a queixa foi retirada (MINISTÉRIO DA SAÚDE, 2015).

Em 2005, o governo brasileiro recusou a ajuda financeira do programa do governo norte-americano Pepfar (Plano de Emergência do Presidente para a assistência à AIDS - President's Emergency Plan for AIDS Relief) por conta dos condicionantes ao empréstimo. Entre as exigências, o programa pedia a condenação pública da prostituição e a exclusão desse grupo da política. Além disso, tinha como diretriz o incentivo à abstinência, a chamada política do ABC (abstinence, be faithful, condomise - abstinência, fidelidade e preservativo), que foi considerada pelo órgão retrógrada e insuficiente para a resposta brasileira (DIAHV, 2015).

Desde sua instauração, o programa de AIDS brasileiro tem sido considerado um exemplo bem sucedido de prestação de serviços de cuidado em HIV com o engajamento da sociedade civil (PARKER, 2003; BERKMAN et al., 2005). Como a descentralização do sistema de saúde criou a necessidade de associação entre a burocracia central e movimentos sociais locais, esses grupos serviram de ponte para implementar as políticas de HIV na ponta (RICH, 2013). Além disso, o programa conta com espaços de incidência política da sociedade civil, sendo os principais a Comissão Nacional de DST, AIDS e Hepatites Virais (Cnaids) e a Comissão de Articulação com os Movimentos Sociais (Cams). O Brasil também esteve na vanguarda global ao fornecer tratamento universal gratuito e por ter garantido a produção de medicamentos antirretrovirais nacionalmente (PARKER, 2003).

10 “AZT ou ZDV, um dos primeiros nucleosídeos da transcriptase reversa (NRT) aprovados pela Food and Drug Administration (FDA) - a agência de vigilância sanitária dos Estados Unidos da América - em 1987, é um medicamento utilizado para retardar o desenvolvimento da AIDS” (UNAIDS, 2017). 
Uma característica do perfil gestor da política de AIDS no Brasil é a entrada de militantes de movimentos sociais nos quadros técnicos. A partir da década de 1990, vários membros de organizações da sociedade civil com atividades em HIV/AIDS passaram a integrar a equipe do programa nacional (GALVÃO, 2000, p. 101). Desde então, é comum que ativistas sejam convidados a compor quadros burocráticos.

É importante notar que a consolidação da política nesse primeiro momento deu base para as grandes transformações ao longo dos anos e permitiu que diversos atores se mobilizassem ao redor da pauta. O envolvimento e a incorporação de movimentos sociais na agenda do governo também são práticas que têm sido adotadas desde o início da política e um traço importante da identidade e da atuação da instituição.

\subsection{O Ministério da AIDS - consolidação da autonomia organizacional}

Conforme observamos ao longo do histórico, a identidade construída por várias lutas políticas e momentos de afirmação ajudou a criar uma forma de atuação da resposta à AIDS no Brasil, baseada na combinação entre especialização técnica e forte interação com movimentos sociais. A visibilidade da política, por conta do vírus e da reputação internacional da reação brasileira, acabou por criar ao redor da instituição uma aura de excepcionalidade dentro do Ministério da Saúde.

O arranjo administrativo e financeiro da política também reforçou seu caráter singular. Os recursos provenientes do Banco Mundial a partir de 1994 possibilitaram autonomia em relação aos recursos do governo federal. Nesse contexto, um dos ministros da saúde (entre 1996-1998) apelidou a instituição de "Ministério da AIDS", conforme relata a seguinte entrevista:

Esse ministro [Carlos] Albuquerque, [...] ele chamava o Programa de AIDS de Ministério da AIDS. Sempre quando marcava audiência com ele que ia na sua sala, ele vinha, abria a porta, e falava "Boa tarde, Ministro da AIDS". Era uma forma jocosa obviamente, era uma crítica, mas era uma forma meio de revanche. (Entrevista 20, 27 set. 2017). 
Nos primeiros anos da política, isso era especialmente enfatizado, tanto por conta da quantidade de recursos quanto pela capacidade e especialização técnica dos funcionários. Assim como o ministro da saúde anteriormente citado, uma das pessoas entrevistadas compara a organização da política a um ministério paralelo.

[Era] como se fosse um ministério paralelo, era assim que era entendida a resposta, porque você tinha toda uma estrutura repetida numa escala menor, você tinha comunicação numa escala menor, você tinha a área internacional numa escala menor. Você tinha de fato um ministério paralelo que também por conta dos PRODOCS ${ }^{11}$ funcionava de um jeito muito independente, muito com a participação do Banco Mundial. (Entrevista 5, 2 jun. 2012, Brasília).

Para melhor compreender o porquê dessa disposição peculiar da política, e como isso foi se transformando ao longo do tempo, é preciso observar a forma como os recursos do Banco Mundial para AIDS operavam no Brasil. Com o primeiro empréstimo do banco, foram definidas condições para a aplicação dos fundos. Entre elas, o estabelecimento de uma equipe técnica especializada para a implementação, o monitoramento e a avaliação das ações do programa.

No Brasil, desde o início do projeto, o recebimento dos repasses, a contratação de consultores e a especialização organizacional foram processos levados a cabo por meio da estrutura estatal para evitar que a política fosse descontinuada, a exemplo do que havia acontecido na Argentina (ROCHA, 2001). No caso portenho, os recursos foram implementados paralelamente ao Estado por uma equipe gestora própria do Banco Mundial, fora da alçada do Ministério da Saúde, conforme observado por um dos entrevistados:

O Banco Mundial quando chegou, queria criar, como fez na Argentina - e eu estive trabalhando na Argentina e vi realmente o desastre que foi o projeto Lusida - o Banco queria criar um projeto à parte da estrutura do Ministério [da Saúde] [...]. A Lair [Guerra] foi bastante incisiva nisso, ela

${ }^{11}$ Programa de Apoio a Projetos Institucionais com a Participação de Recém-Doutores. 
discordou completamente, e o programa passou a ser também o gestor do recurso do Banco Mundial. Na Argentina, o que aconteceu: criaram o projeto Lusida, e tinha o programa de AIDS, que corria em paralelo. Quando acabou o Lusida, o programa de AIDS praticamente não existia e continua a não existir praticamente, porque não havia recursos... e o Lusida acabou e todo mundo se dispersou. O programa de AIDS [no Brasil] não, o projeto do Banco acabou e o Ministério assumiu toda aquela estrutura que era antes financiada pelo Banco Mundial. (Entrevista 20, 27 set. 2017).

Essa identidade marcou de maneira profunda a atuação dos gestores e influenciou de forma direta a sua reação a mudanças. Como a política espelhava a estrutura de um programa de organização internacional, havia uma proposta de autossuficiência que foi absorvida pelo Ministério da Saúde.

A partir desse processo, a política ficou organizada em especialidades técnicas, e definiu-se uma rede hierárquica entre os gestores. Por ser um programa, havia certa flexibilidade para que isso acontecesse. Conforme explica uma das pessoas entrevistadas, essa especialização progressiva resultou em diferentes chefes de área, que se organizavam de acordo com as necessidades da epidemia. A partir do empréstimo AIDS 3, essa "superestrutura" foi consolidada oficialmente pela entidade, e os chefes tiveram seu poder legitimado.

O que acontece, quando você tem um empréstimo do Banco Mundial, lá na década de 1990, quando chega o primeiro empréstimo, o programa começa a se organizar estruturalmente. Essa estrutura segue uma lógica do que se dizia que era a lógica das epidemias, das endemias. A lógica das epidemias é você ter uma unidade de vigilância, uma unidade de assistência. Na verdade, do ponto de vista da vigilância é uma unidade de vigilância e o pessoal do planejamento, então você vai aí juntando... Qual foi o diferencial do Brasil nessa época: ele criou uma unidade de sociedade civil. Quando a gente começa a ter testes para fazer exame de HIV, pra fazer fluxograma de quantas vezes tira sangue -0 [teste] western blot - você começa a ter gente que lide com laboratório, [...] com o passar do tempo, essas áreas especializadas elas vão ganhando força. E aí chega um momento que num 
dos empréstimos, que se não me engano foi o AIDS 3, ele determina claramente essa superestrutura, esse organograma, que cada uma dessas unidades tem um chefe, só que ele era naquele momento chefe de verdade do programa. ${ }^{12}$

Outra característica importante dessa organização é que o coordenador do programa poderia ter interlocução direta com os estados e municípios, encaminhando os recursos do Banco Mundial e desenvolvendo as ações sem precisar passar pelo Secretário de Vigilância em Saúde, conforme mencionado pela entrevista a seguir:

Veja, quando você é programa você flutua, você pode ter 500 pessoas trabalhando pra você, 20 áreas, entendeu. O programa tinha várias áreas técnicas, mas o que acontece, essas áreas técnicas atuavam direto com estados e municípios sem que isso fosse a prática do SUS. Então já existia uma discussão que era o programa passar a atuar mais integrado ao SUS. Sempre foi SUS, mas atuar como se fosse, porque existe toda uma hierarquia do SUS, você tem que lidar com secretários [dentro do Ministério da Saúde, e nos estados e municípios]. Então alguns estados, o ponto focal de AIDS tinha mais poder do que o pessoal da atenção básica por exemplo, era muito poder, porque era muito dinheiro envolvido, os recursos iam [direto] para estados e municípios. ${ }^{13}$

Essa autossuficiência possibilitou que as ações do departamento fossem desenvolvidas em paralelo não só aos recursos financeiros do Ministério da Saúde, mas também sem a necessidade explícita de apoio técnico de outras unidades do órgão. Uma das consequências disso é que a especialização técnica dos quadros cria uma grande complexidade no processo decisório.

\footnotetext{
${ }^{12}$ Assim como em minha dissertação (CARTAXO, 2018), oculto o número da entrevista com vistas a preservar o anonimato da pessoa entrevistada

${ }^{13}$ Para manter o anonimato da entrevista, optou-se por omitir o seu número.
} 
Por outro lado, como explica uma das entrevistas, os saldos dessas decisões são positivos por serem resultado de um trabalho a muitas mãos.

O que eu digo é que essa estrutura que a gente tem é engomosa, ela é difícil de andar. Tudo parece lento, mas quando sai, sai muito bem feito, entendeu. Tudo que é produzido aqui é muito precioso. Agora, demora pra produzir, por causa desse diálogo interno, que é engomoso, é demorado. ${ }^{14}$

Por mais que houvesse robustez no desempenho da política pública, a condição de programa ainda trazia certa fragilidade com relação à continuidade da resposta à AIDS dentro do Ministério da Saúde. Sendo um programa, não havia estabilidade institucional, e por mais que houvesse flexibilidade interna, a política ainda estava no patamar mais baixo da hierarquia do Ministério da Saúde. Nesse momento, a diretoria começou a discutir com a Secretaria de Vigilância em Saúde a possibilidade de ascensão hierárquica da política de AIDS e de DST.

\subsection{A transformação em departamento}

Durante a gestão da diretora Mariângela Simão (2006-2010), a política de AIDS passou por uma grande transformação interna. Em 2009, o Programa de DST/AIDS do Ministério da Saúde passou a integrar a estrutura da Secretaria de Vigilância em Saúde (SVS) como departamento, não mais como programa. O Decreto $n^{\circ} 6.860$, de 2009, também definiu a incorporação do programa de Hepatites Virais a suas atribuições, centralizando a aquisição dos medicamentos desse agravo naquele órgão. Dessa forma, o programa tornou-se Departamento de Vigilância, Prevenção e Controle das IST, do HIV/AIDS e Hepatites Virais.

Ao longo de mais de 30 anos da política de AIDS, o Diahv passou por diversas mudanças organizacionais. A transformação em departamento aumentou o patamar da política de AIDS dentro do Estado. Ao integrar a Secretaria de Vigilância em Saúde, essa instituição se tornava não apenas

${ }^{14}$ Para manter o anonimato da entrevista, optou-se por omitir o seu número. 
uma política de governo, mas também uma política de Estado, garantindo a continuidade da resposta à epidemia de HIV em longo e médio prazo, a despeito de mudanças na condução do executivo nacional. As implicações dessa transformação são o terreno de interpretações divergentes dos gestores envolvidos.

Segundo entrevistas, o debate vinha sendo travado internamente ao longo de vários anos no Ministério da Saúde, mas apenas em 2009, durante a gestão de Mariângela Simão, a mudança se consolidou de fato, conforme explicado a seguir:

Primeiro que tem um entendimento errado, e provavelmente ainda tem, por parte de somente alguns setores da sociedade civil, de que teria sido uma perda virar departamento. [Isso] é uma bobagem, porque na verdade foi a institucionalização de um status dentro do Ministério, porque por exemplo à época [...] você tinha o Ministro da Saúde, [o] Secretário Executivo e os secretários das áreas específicas, e abaixo dos secretários, você tem os departamentos, e abaixo do departamento você tem os programas, certo? Então na verdade o interesse e a movimentação para que o programa que estava lá embaixo na cadeia alimentar do Ministério, mas estava bem do ponto de vista político, de que o programa fosse institucionalizado como departamento, começou na época do Alexandre Granjeiro [ex-coordenador], que quando estava [na direção] iniciou o processo, com a reforma administrativa do Ministério. (Entrevista 18, 12 set. 2017).

A partir desse acontecimento, o HIV passou a ter um status elevado em relação a outros agravos, e o Secretário de Vigilância em Saúde passou a ser o encarregado direto da pasta. Anteriormente, enquanto programa, a política estava subordinada ao Departamento de Vigilância Epidemiológica.

Ao mudar de patamar, o órgão também absorveu a responsabilidade das Hepatites Virais, assumindo novas funções. Após anos de funcionamento com um número considerável de funcionários divididos por áreas temáticas, mais um componente foi adicionado à logística da organização. Para que toda a estrutura fosse consolidada no quadro ministerial, no qual o 
organograma e o número de cargos de confiança são definidos por medida provisória, algumas adaptações foram feitas, como a fusão de coordenações existentes em áreas temáticas. Isso acabou dissolvendo e reagrupando a organização estabelecida em formato de programa, que englobava várias áreas temáticas. As redes pré-estabelecidas foram abaladas e os antigos chefes perderam a posição que outrora ocupavam.

A partir da transformação em Departamento, as responsabilidades foram limitadas a duas coordenações: i) Coordenação-Geral de Ações Estratégicas em IST, AIDS e Hepatites Virais; e ii) Coordenação-Geral de Vigilância e Prevenção de IST, AIDS e Hepatites Virais, com seis cargos de confiança. Isso não foi uma mudança fácil para os gestores, conforme esclarece o seguinte trecho:

Então essa política foi responsável por toda uma organização programática, por todo um grupo de pessoas, uma tomada de decisão muito forte, tinha muito dinheiro envolvido, os empréstimos do banco mundial, então isso aí fez toda uma diferença pra essa fortaleza. Aí você imagina colocar tudo isso aí dentro de um departamento. A princípio caberia, o que tinha que ser feito? Atuar dentro das regras do SUS, mas essa atuação foi um processo traumático, porque as pessoas que trabalhavam aqui na época tinham uma sensação de muita liberdade, muita autonomia. ${ }^{15}$

A entrevista a seguir explica como aconteceu essa mudança, quando o grande número de áreas temáticas ficou reorganizado dentro de três coordenações.

As áreas continuam existindo, mas precisaram ser submetidas a uma nova hierarquia interna. Com a criação do departamento não foram as ações que foram restringidas mas sim a estrutura organizacional. Anteriormente, tínhamos unidades e assessorias estruturadas em função das suas atribuições funcionais e com o Decreto n ${ }^{\circ}$ 6860/2009 que cria o departamento

${ }^{15}$ Para manter o anonimato da entrevista, optou-se por omitir o seu número. 
estabelece uma estrutura formada por duas coordenações técnicas e uma coordenação administrativa. Mas continuamos funcionando em conformidade às nossas necessidades e atribuições de forma oficiosa para não quebrar a sintonia e organicidade interna. (Entrevista 8, 26 mai. 2017).

Segundo uma das entrevistas, essa mudança causou certo desconforto entre os funcionários, pois eles se viram submetidos a uma nova ordem mais centralizada, com menor autonomia para os chefes temáticos. A rede informal previamente consolidada foi quebrada, conforme explica uma das entrevistas.

Esses chefes [de áreas temáticas] não podem assinar nada. Só quem assina é quem tem cargo. Então não importa quantas pessoas estejam atrás da diretora, só ela e seus dois substitutos que assinam - essas três pessoas. Então você imagine que antes saía memorando de um canto para outro, a unidade técnica, a assessoria pra lá. Essa circulação de documentos não existe mais, isso foi uma questão burocrática que foi realmente uma regulamentação. (Entrevista 13, 16 jun. 2017, Brasília).

Quando o programa era vinculado de forma distante à hierarquia do Ministério da Saúde, ele tinha a liberdade de definir sua própria organização. Os chefes das áreas temáticas, mesmo sem cargo, tinham responsabilidades e autonomia. Com a transformação do programa de AIDS em departamento, essa flexibilidade foi desfeita e as redes dissolvidas. Os chefes de área, que possuíam autonomia administrativa e responsabilidades dentro da hierarquia, perderam o status, mesmo que ainda mantivessem as mesmas atribuições.

Na medida em que o programa foi entrando na estrutura do Ministério [...] a questão da autonomia, a ideia de que você pode responder diretamente pelas coisas, que eu acho positiva na agenda pública [...] você se perde um pouco nesse organograma, então quem responde é sempre uma hierarquia [...] e a AIDS tinha muito esse protagonismo. [...] Na hora que vira departamento essa figura [do chefe de área temática] não existe mais, ela está ali mas ela não 
assina um documento, não passa documento para outra área. Desburocratizou isso, e para muitos deles isso foi muito difícil, então muitos desses chefes foram embora [...] Eu vi vários saírem, vários chefes, unidade de DST se acabou, unidade de laboratório permaneceu, a unidade de sociedade civil juntou com prevenção, porque eram separadas. E aí hoje houve um reagrupamento. (Entrevista 13, 16 jun. 2017).

As áreas temáticas dentro do arranjo de programa passaram por uma reconfiguração, tentando ao máximo manter em operação todas as áreas que vinham trabalhando dentro do órgão. Para acomodar essa organização, foi definido um arranjo informal que orientava o trabalho cotidiano dos gestores.

Segundo uma das entrevistas, essa estrutura organizacional peculiar e a mudança na flexibilidade anterior trouxeram dificuldades de adaptação para os funcionários, visto que compõem uma realidade diferente de outras doenças trabalhadas no Ministério da Saúde. Após a dissolução das redes de trabalho anteriores, houve uma grande dificuldade em operar dentro da organização do Ministério da Saúde.

Aqui é uma superestrutura, que eu não diria paralela ao ministério porque está integrada, está dentro do departamento, mas são pessoas assim no final das contas que vivem no seu próprio mundo, porque não entendem a lógica do ministério. Muitos deles, que entraram depois, não entendem a lógica do ministério porque não vivem, vivem aqui dentro nessa estrutura. ${ }^{16}$

Alguns gestores argumentam que, com a transformação política, perdeu-se a interlocução com o alto escalão do Ministério. Questionam a mudança nos relacionamentos e na liberdade autoral que se concedia às ações da política. Vemos certo paradoxo pois, por mais que houvesse maior importância hierárquica, isso não foi claramente traduzido em aproximação com o alto nível do poder. Para um dos relatos, enquanto programa a

${ }^{16}$ Para manter o anonimato da entrevista, optou-se por omitir o número. 
política tinha um trato melhor com o ministro, por ter acesso direto a ele e liberdade em fazer publicações:

O programa de AIDS tinha autonomia, tinha acesso direto ao ministro, sabe? Nós tínhamos a nossa editoração de documentos, não dependia do Ministério, publicava, tinha realmente autonomia de decisão técnica e política também, na medida em que tinha acesso direto ao ministro, e isso foi bastante claro nos anos 1980, 1990. (Entrevista 20, 26 set. 2017, Brasília).

A integração no Ministério da Saúde acabou sendo interpretada por alguns como burocratização e engessamento das funções do Diahv. Mesmo assim, um dos relatos ressalta que isso se confunde com a conjuntura política mais ampla.

O que eu percebi foi que a gente ficou um pouco mais engessado, mas eu não sei se foi pela mudança de programa para departamento ou pela própria conjuntura do Ministério que mudou mesmo. Eu percebo que a gente tinha um pouco mais de liberdade. ${ }^{17}$

Contudo, a força da autonomia da política não é unanimidade entre os entrevistados. Para um dos gestores, o isolamento do departamento separava as ações realizadas pelo Diahv do resto dos programas do Ministério da Saúde, e isso precisava ser modificado para conseguir avançar a luta contra a epidemia.

No campo da política, [a] principal tarefa era tirar o departamento do isolamento que ele tinha dentro do Ministério da Saúde, é como ele se não fosse parte [do Ministério da Saúde]. [...] O fundamental era garantir primeiro que a política pública permanecesse, ela não fosse isolada como política pública, que ela atualizasse, que tivesse uma versão 2.0, e que ela não perdesse nenhum dos ganhos históricos que ela teve e que ao contrário, que a gente conseguisse aprofundar num curto espaço de tempo para recuperar o tempo perdido e para colocar a epidemia sob controle. (Entrevista 19, 15 set. 2017, Brasília).

${ }^{17}$ Para manter o anonimato da entrevista, optou-se por omitir o número. 
Outra entrevista reforça, ainda, essa perspectiva. Para o respondente em questão, o grande problema é que esse organograma abrangente e especializado acabou por tornar o trabalho do departamento tão independente a ponto de separá-lo da lógica do Ministério. Isso é considerado prejudicial porque, ao mesmo tempo em que há autonomia, continua a existir a necessidade de operar dentro da lógica organizacional federal. Os gestores acabam vivendo "em seu próprio mundo".

Isso [...] é quase uma secretaria na estrutura de um departamento. Só comparar com a tuberculose, com a malária, todos eles estão dentro de um departamento. Existe o Devit, e lá dentro tem a coordenação de tuberculose, coordenação de malária, e essas pessoas fazem a mesma atividade programática com bem menos gente, lidando com atenção básica, coisa que aqui não é assim. Aqui é uma superestrutura, que eu não diria paralela ao ministério porque está integrada, está dentro do departamento, mas são pessoas que, no final das contas, vivem no seu próprio mundo, porque não entendem a lógica do Ministério, muitos deles, não entendem a lógica do Ministério porque não vivem. ${ }^{18}$

A perda de autonomia não é consenso entre os entrevistados. Para alguns, a transformação moveu o departamento no sentido contrário.

Quando você é um programa, [...] mais subordinação você tem acima de você, para você ver: tem programa, aí você tem departamento, aí você tem secretaria, e aí você tem ministro. E o fato de estarmos como departamento agora, isso já te dá uma autonomia maior, e uma facilidade de você chegar aos gestores maiores da instituição, porque de departamento você só tem o secretário e de secretaria você tem o ministro, quer dizer, essa mudança de estrutura viabiliza melhor os nossos trâmites administrativos, políticos e técnicos, então a facilidade de interlocução para a gente como departamento é bem melhor. (Entrevista 15, 31 jul. 2017, Brasília).

${ }^{18}$ Para manter o anonimato da entrevista, optou-se por omitir o número. 
Antes da mudança para departamento, a organização administrativa e gerencial dava maior visibilidade para as áreas temáticas e para as redes de pessoas que eram estruturadas ao redor delas. No momento em que essa organização foi rompida, os gestores passaram a enxergar essa nova ordem como um rompimento da antiga forma de fazer a política e, consequentemente, da identidade autônoma da política pública. Segundo as entrevistas, antes redes autogestionadas ditavam as decisões técnicas e as relações da instituição com estados e municípios. Após a transformação, alguns gestores interpretaram que o “engessamento” burocrático dissolveu as possibilidades de ação.

A transformação organizacional do Programa Nacional de AIDS em departamento da SVS foi o marco de um processo mais amplo de transformação que envolve interpretações sobre: i) a institucionalização da política; e ii) a autonomia da organização. Opiniões sobre esses dois movimentos podem ser identificadas nas falas dos atores entrevistados, discursos muitas vezes divergentes. Além disso, concepções sobre a autonomia organizacional e individual amiúde se sobrepõem, trazendo à tona a discussão sobre autonomia como capacidade, ressaltada por Abers e Santiago (2017).

Seguindo a lógica de DiMaggio (1988), compreendemos a institucionalização como um processo que reflete o poder relativo de interesses dos atores e sua capacidade de mobilização. Destarte, esse processo gera interpretações sobre as mudanças do Diahv, entre visões dos limites impostos pela conjuntura política e visões da institucionalização e autonomia do departamento. Dentro de cada um desses debates, temos o olhar para uma parte específica da política ou para um acontecimento particular. A forma como os gestores enxergam a identidade da política foi alterada nesse momento de transformação.

As falas apresentadas mostram como a mobilização ao redor da autonomia da política é um ponto importante para os gestores. A construção histórica da política pública, por meio da força das características organizacionais do Diahv, acabou por consolidar um mito nativo sobre a instituição, que não necessariamente é compartilhado por todos. Esse mito estabeleceu um olhar particular sobre as atribuições do departamento e o modo como a política pública deveria se comportar dentro do quadro do Ministério da Saúde. Assim como Hallett e Ventresca (2006) observam em Gouldner, o momento anterior à transformação em departamento pode ser definido como um “mito de Rebecca”, onde 
há idealização do quadro organizacional anterior e uma memória do padrão indulgente que continua sendo mobilizada pelos funcionários. ${ }^{19}$

Oito anos após a transformação, gestores relatam que ainda estão se adaptando e que, até o momento, não foi absorvida por todos. A manutenção da estrutura organizacional em várias áreas técnicas, apesar de não ter mantido a autonomia dos gestores que chefiavam esses grupos, procurou manter a identidade característica da política de AIDS e, de certa forma, garantir a continuação do que estava sendo feito.

Por outro lado, a controvérsia em torno da autonomia do Diahv acaba por influenciar a forma como os gestores enxergam as próprias capacidades. Em locais de trabalho contruídos tendo em vista uma política autônoma, a visão sobre as possibilidades de atuação dos gestores é ampliada. Cabe notar que as transformações a nível de alto escalão também afetam a percepção dos atores sobre a autonomia individual e organizacional, nos termos do debate proposto por Abers e Santiago (2017).

Voltando a DiMaggio (1988), afirmamos que o processo de institucionalização - que por vezes ocorre de forma problemática - é baseado especialmente no trabalho prático dos atores. Esse trabalho é ancorado nos significados construídos pelas pessoas sobre sua ação social. Nesse momento, a construção da identidade da política pública afetou a forma como os indivíduos entrevistados interpretaram a mudança. As críticas dos gestores às transformações indicam que os burocratas notaram uma alteração nos recursos necessários ao burocrata para que tome suas decisões, e isso afetou diretamente a forma como enxergam o próprio trabalho.

A partir da análise das entrevistas, observa-se que a mudança organizacional e contextual da posição da política de AIDS dentro do Ministério da Saúde é um assunto de preocupação para os entrevistados, e que esse tema está em disputa entre os diferentes gestores envolvidos. As capacidades e

${ }^{19}$ Para construir o conceito de "mito de Rebecca”, Gouldner (1954) busca inspiração no livro Rebecca (1938) de Daphne du Maurier, no qual descobre-se ao final que a mulher idealizada, Rebecca, era na verdade cruel e descompensada. Nesse capítulo, trazemos o mito de Rebecca como uma alegoria para uma ordem organizacional anterior e como uma categoria nativa para explicar a mudança de paradigma institucional, sem, necessariamente, chegar a um juízo de valor negativo ao final da análise. 
a autonomia do órgão dependem de uma série de variáveis institucionais e políticas em constante construção.

A história da política instituiu uma ordem social baseada na legitimidade das áreas temáticas e na autonomia de aplicação da política. Conforme Emirbayer e Goodwin (1994), a autonomia individual não é concebida sozinha, mas é resultado da interface entre identidade e relações em rede. A consolidação histórica da política gerou um modus operandi que ganhou legitimidade externa e aceitação interna, de modo que qualquer mudança seria vista como uma influência ao modo de operar.

As redes ativistas consolidadas no início da epidemia foram a base da sociabilidade e das formas de trabalho dos gestores. A transformação organizacional acabou abalando práticas consolidadas de atuação institucional e causando certo estranhamento por parte dos gestores. Por outro lado, essa mudança se confunde com outros acontecimentos no contexto do Ministério da Saúde, onde crises políticas resultaram na saída de dois diretores da chefia do departamento (CARTAXO, 2018). Dessa forma, por mais que a mudança organizacional seja um gatilho para uma crítica à mudança, a visão otimista da ordem anterior também pode ser relacionada a um momento político mais favorável dentro do Ministério da Saúde.

Por mais que não seja a única explicação para as diferentes interpretações sobre a mudança da política, essa transformação organizacional é um marco importante para sua consolidação e afetou diretamente a dinâmica de atuação dos indivíduos. Observar as diferentes interpretações sobre esse momento ajuda a ter uma visão próxima de como a sociabilidade e o histórico da política afetam a organização social e geram controvérsias sobre o local de trabalho dos gestores.

\section{Considerações finais}

A política de AIDS continua a ser uma das respostas nacionais com maior visibilidade e com o maior número de recursos do governo federal. A sua subsistência exige a mobilização contínua dos gestores e uma grande equipe é responsável por mantê-la viva e relevante dentro do Ministério da Saúde. Conforme visto no histórico, o ativismo, por meio de uma 
coordenação de articulação social, é uma característica importante da sociabilidade dos gestores e da própria organização das ações.

Observamos que os significados construídos pelos gestores sobre a transformação da política dizem respeito a uma forma de atuação característica que foi consolidada ao longo de vários anos de política pública. Na medida em que foi instaurada uma controvérsia sobre essa mudança, defendemos que um "mito de Rebecca” (HALLETT; VENTRESCA, 2006) tomou lugar nas interpretações sobre o momento anterior à consolidação do departamento.

Esse mito afetou as percepções sobre a legitimidade e autonomia dos indivíduos, pois as redes de trabalho anteriores foram dissolvidas dando lugar a uma nova ordem institucional. A legitimidade informal, criada por laços de confiança previamente estruturados entre as áreas temáticas, foi abalada. A decisão tomada por órgãos superiores do Ministério da Saúde e articulada pelos diretores afetou os gestores de nível técnico ao criar uma nova dinâmica de interação entre eles.

As visões subjetivas analisadas ajudam a compreender como as práticas institucionais significam e moldam as narrativas, pois a partir delas podemos compreender a linha de raciocínio por trás das organizações políticas. Por meio da análise dos efeitos dessa nova forma de gestão, é possível ler as interações e os processos que criam e abalam a ordem social. Os gestores não são passivos ao receber as mudanças e eles as interpretam de acordo com sua realidade (HALLETT; VENTRESCA, 2006).

A partir do exemplo do Departamento de IST, AIDS e Hepatites Virais do Ministério da Saúde, reforçamos que as instituições são ambientes habitados por indivíduos e precisam ser analisadas por meio de suas interações e significados sociais. Essa abordagem é importante para que se possa expandir a compreensão sobre a atuação de órgãos do Estado na implementação de políticas públicas.

Por outro lado, no contexto de uma política pública construída por meio do ativismo, a análise de como os indivíduos enxergam o local de trabalho é bastante influenciada por conceitos e prioridades ativistas. Ao longo das entrevistas, pudemos notar que a mudança organizacional não causou apenas o rompimento da ordem anterior, mas também abalou os conceitos pré-construídos de como a política pública deveria atuar e de como seria mais efetivo o envolvimento do gestor. 
A agenda de pesquisa do ativismo institucional envolve uma ampliação do debate sobre o papel do ator nas instituições. Mostramos que as interpretações dos gestores sobre as mudanças têm um papel explicativo importante sobre a dinâmica institucional, e que burocratas têm suas dinâmicas afetadas por decisões top down. Para avançar ainda mais na compreensão do papel do ativismo na ação burocrata, estudos de interpretações subjetivas sobre mudanças são bastante úteis porque capazes de relacionar, de maneira equânime, aspectos organizacionais e o trabalho interativo dos gestores.

\section{Referências}

ABERS, Rebecca Neaera; SANTIAGO, Ariadne. A autonomia do burocrata técnico: o caso do licenciamento ambiental do Ibama. In: DE PAULA, Jean Marla P. et al. (org.). Burocracia federal de infraestrutura econômica: reflexões sobre capacidades estatais. Brasília: Ipea, 2017.

ABERS, Rebecca Neaera; SERAFIM, Lizandra; TATAGIBA, Luciana. Repertórios de interação estado-sociedade em um estado heterogêneo: A experiência na era Lula. Dados - Revista de Ciências Sociais, Rio de Janeiro, v. 57, n. 2, p. 325-357, 2014.

BERKMAN, Alan et al. A critical analysis of the Brazilian response to HIV/AIDS: lessons learned for controlling and mitigating the epidemic in developing countries. American Journal of Public Health, v. 95, n. 7, p. 1162-1172, 2005.

BRANDÃO, Igor Ribas. VILAÇA, Luiz Henrique. Ativismo burocrático na construção de Belo Monte e na inclusão socioprodutiva de catadores de materiais recicláveis. Anais. In: ENCONTRO INTERNACIONAL PARTICIPAÇÃO, DEMOCRACIA E POLÍTICAS PÚBLICAS, 3., 2017, Vitória/ES. Anais [...] Vitória/ES: Universidade Federal do Espírito Santo (UFES), 2017. 
BRANDÃO, Igor R.; VILACA, Luiz. Ativismo burocrático na construção de Belo Monte e na inclusão socioprodutiva de catadores de materiais recicláveis. In: ENCONTRO INTERNACIONAL PARTICIPAÇÃO, DEMOCRACIA E POLÍTICAS PÚBLICAS, 3., 2017, Vitória/ES. Anais [...] Vitória/ES: Universidade Federal do Espírito Santo (UFES), 2017.

BRASIL. Ministério da Saúde. Departamento de Vigilância, Prevenção e Controle das IST, do HIV/Aids e das Hepatites Virais. História Ilustrada da AIDS, 2014, 7 min., son., color. Disponível em: https://www.youtube. com/watch?v=ShaCZ9b1MKs. Acesso em: 27 ago. 2018.

CARTAXO, Mariana. A política de AIDS: conflitos e transformações. 2018. 100 f., il. Dissertação (Mestrado em Ciência Política) - Instituto de Ciência Política, Universidade de Brasília, Brasília, 2018.

DIMAGGIO, Paul. Interest and agency in institutional theory. In: ZUCKER, Lynne G. (org.). Institutional patterns and organizations: culture and environment. Pensacola, Florida: Bellinger Publishing, 1988.

EMIRBAYER, Mustafa; GOODWIN, Jeff. Network analysis, culture, and the problem of agency. The American Journal of Sociology, v. 99, n. 6, p. 1411-1454, 1994.

EMIRBAYER, Mustafa; MISCHE, Ann. What is agency? American Journal of Sociology, v. 103, n. 4, p. 962-1023, 1998.

GALVÃO, Jane. AIDS no Brasil: a agenda de construção de uma epidemia. Rio de Janeiro: Associação Brasileira Interdisciplinar de AIDS, 2000.

GOULDNER, Alvin W. Patterns of industrial bureaucracy. Glencoe: Free Press, 1954.

HALLETT, Tim; VENTRESCA, Marc J. Inhabited institutions: social interactions and organizational forms in Gouldner's "Patterns of Industrial Bureaucracy”. Theory and Society, v. 35, n. 2, p. 213-236, 2006. 
LAWRENCE, Thomas B.; SUDDABY, Roy; LECA, Bernard. Introduction: theorizing and studying institutional work. In: LAWRENCE, Thomas B.; SUDDABY, Roy; LECA, Bernard. (org.). Institutional work actors and agency in institutional studies of organization. Cambridge, New York: Cambridge University Press, 2009.

MACRAE, Edward. A construção da igualdade: identidade sexual e política no Brasil da “abertura”. Campinas: Editora da Unicamp, 1990.

MENICUCCI, Telma M. G. Os argumentos analíticos: a perspectiva histórica e institucional. In: MENICUCCI, Telma M. G. Público e privado na política de assistência à saúde no Brasil: atores, processos e trajetória. Rio de Janeiro: Editora Fiocruz, 2007.

MISCHE, Ann. De estudantes a cidadãos: redes de jovens e participação política. Revista Brasileira de Educação, n. 5-6, p. 134-150, 1997.

OLIVEIRA, Marília Silva de. Movimento para as instituições: movimento ambiental, partidos políticos e a liderança de Marina Silva. 2016. 303 f., il. Tese (Doutorado em Ciência Política) - Instituto de Ciência Política, Universidade de Brasília, Brasília, 2016. PARKER, Richard. Building the foundations for the response to HIV/AIDS in Brazil: the development of HIV/AIDS policy, 1982-1996. Divulgação em Saúde para Debate, v. 27, p. 143-183, 2003.

RICH, Jessica. Grassroots bureaucracy: intergovernmental relations and popular mobilization in Brazil's AIDS policy sector. Latin American Politics and Society, v. 55, n. 2, p. 1-25, 2013.

ROCHA, Laura. Polémica por el fin del proyecto Lusida. La Nación, Buenos Aires, 10 dez. 2001. Disponível em: https://www.lanacion.com.ar/357997polemica-por-el-fin-del-proyecto-lusida. Acesso em: 27 ago. 2008.

SANTIAGO, Ariadne. Capacidades burocráticas na prática: um olhar através das lentes dos analistas do licenciamento ambiental federal. 2017. 187 f., il. Dissertação (Mestrado em Ciência Política) - Instituto de Ciência Política, Universidade de Brasília, Brasília, 2017. 
SEWELL, William H. Jr. A theory of structure: duality, agency, and transformation. The American Journal of Sociology, v. 98, n. 1, p. 1-29, 1992. TEIXEIRA, Paulo Roberto. Políticas públicas em AIDS. In: PARKER, R. (org.). Políticas, instituições e AIDS: enfrentando a epidemia no Brasil. Rio de Janeiro: ABIA, Jorge Zahar, 1997.

UNAIDS. Guia de Terminologia do UNAIDS. Brasília: Casa da ONU, 2017. UNAIDS. UNAIDS: the first ten years, 1996-2006. Geneva, Switzerland: Joint United Nations Programme on HIV/AIDS, 2008.

VIANA, Rafael Rocha. Programa Minha Casa Minha Vida - Entidades: um olhar para a ação dos atores em torno das controvérsias. 2017. 147 f., il. Dissertação (Mestrado em Ciência Política) - Instituto de Ciência Política, Universidade de Brasília, Brasília, 2017.

VILAÇA, Luiz. De práticas a capacidades: a atuação de procuradores do Ministério Público Federal no caso de Belo Monte. Soc. e Cult., Goiânia, v. 20, n. 1, p. 61-82, jan./jun. 2017. 